\title{
COVID-19 and Aplastic Anemia: Friend or Foe
}

\author{
Mohd Mustahsin ${ }^{1 *}$, Zeba Siddiqi ${ }^{2}$, Ajay Mishra ${ }^{2}$ and Garima Singh ${ }^{1}$ \\ ${ }^{1}$ Critical Care Unit, Department of Anesthesia and Critical Care, Era's Lucknow Medical College and Hospital, \\ Uttar Pradesh, India
}

${ }^{2}$ Department of Medicine, Era's Lucknow Medical College and Hospital, Uttar Pradesh, India

*Corresponding author: Dr. Mohd Mustahsin, Consultant and Head of Critical Care, Department of Anesthesia and Critical Care, Era's Lucknow Medical College and Hospital, Lucknow, Uttar Pradesh, 226003, India, Tel: +91-987-155-9131

\begin{abstract}
Aplastic Anemia is a rare hematological disorder caused by bone marrow failure leading to pancytopenia. These patients are frequently treated with immunosuppressive therapy which may protect them in developing hyper-inflammatory response which is commonly seen in moderate and severe COVID-19 patients. On the other hand these patients are at high risk for infection and infection related complications. Here we are reporting an adult aplastic anemia patient who developed uncomplicated course of COVID-19 pneumonia.
\end{abstract}

\section{Introduction}

Severe Acute Respiratory Syndrome Coronavirus 2 (SARS-CoV-2), first isolated in Wuhan, China was declared by World Health Organization (WHO) as a pandemic on March 11, 2020 [1]. Old age, comorbidities like diabetes mellitus, hypertension, obesity, smoking, chronic lung diseases and immunosuppression are described as a risk factor for mortality in COVID-19 [2]. Aplastic anemia patients are immunosuppressed either due to the disease itself or due to the treatment given to these patients. On one hand these patients are at high risk of developing severe infections due to low immunity and on the other hand immunosuppression prevents these patients from hyper-inflammation. The literature regarding COVID-19 in aplastic anemia is scarce with only few cases reported till date [3]. Here we are reporting a caseof severe aplastic anemia who developed COVID-19 pneumonia and successfully managed and discharged from the hospital.

\section{Case Report}

A 46-year-old male, known case of severe aplastic anemia was on immunosuppressive treatment and on regular follow-up under hematology, presented to hospital triage (holding area) with history of fever, cough and shortness of breath 5 days after coming in contact with COVID positive patient. His vitals on presentation were pulse rate $96 / \mathrm{min}$, blood pressure $118 / 74$, temperature $100.2{ }^{\circ} \mathrm{F}$, respiratory rate $28 / \mathrm{min}$ and $\mathrm{SpO}_{2}$ $96 \%$ on $5 \mathrm{~L} / \mathrm{min}$ oxygen by facemask. Arterial Blood Gas (ABG) on $5 \mathrm{~L} / \mathrm{min}$ oxygen by facemask showed $\mathrm{pH}$ of 7.52, $\mathrm{pCO}_{2} 31 \mathrm{mmHg}, \mathrm{pO}_{2} 81 \mathrm{mmHg}, \mathrm{HCO}_{3}-25.3 \mathrm{mmol} / \mathrm{L}$ and $\mathrm{SaO}_{2} 99 \%$. His chest $\mathrm{X}$-ray showed bilateral peripheral and lower zone opacities more on left side (Figure 1). HRCT showed patchy areas of ground glass opacities and consolidation in bilateral lung fields (CT severity score $12 / 25$ ). His nasopharyngeal swab for Reverse Transcription Polymerase Chain Reaction (RT-PCR) for SARS-CoV-2 came positive and thus he was shifted to High Dependency Unit (HDU) for further management. He was started on treatment with tablet paracetamol, favipiravir, ivermectin, dexamethasone, vitamin C, co-trimoxazole, fluconazole and prophylactic low molecular weight heparin. His was on tablet cyclophosphamide $100 \mathrm{mg}$ thrice daily which was continued as usual. He was maintained on oxygen by facemask $5 \mathrm{~L} / \mathrm{min}$ and awake self proning was advised. His lab investigations showed, hemoglobin $2.7 \mathrm{~g} / \mathrm{dl}$, Total Leucocyte Count (TLC) $2.5 \times 10^{\%} / \mathrm{L}$, absolute neutrophil count $1.07 \times$ $10^{9} / \mathrm{L}$, absolute lymphocyte count $1.32 \times 10^{9} / \mathrm{L}$, absolute monocyte count $0.07 \times 10^{9} / \mathrm{L}$, platelet count $20 \times 10^{9} / \mathrm{L}$, glucose $152 \mathrm{mg} / \mathrm{dl}$, urea $52 \mathrm{mg} / \mathrm{dl}$, creatinine $1.3 \mathrm{mg} / \mathrm{dl}$, calcium $8.6 \mathrm{mg} / \mathrm{dl}$, albumin $2.2 \mathrm{~g} / \mathrm{dl}$, procalcitonin 0.12 $\mathrm{ng} / \mathrm{ml}$, CRP $64.7 \mathrm{mg} / \mathrm{L}$, Interleukin-6 (IL-6) $56.5 \mathrm{pg} / \mathrm{ml}$,

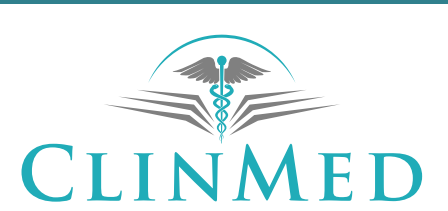

INTERNATIONAL LIBRARY

Citation: Mustahsin M, Siddiqi Z, Mishra A, Singh G (2021) COVID-19 and Aplastic Anemia: Friend or Foe. Int J Blood Res Disord 8:064. doi.org/10.23937/2469-5696/1410064

Accepted: April 26, 2021: Published: April 28, 2021

Copyright: (C) 2021 Mustahsin M, et al. This is an open-access article distributed under the terms of the Creative Commons Attribution License, which permits unrestricted use, distribution, and reproduction in any medium, provided the original author and source are credited. 


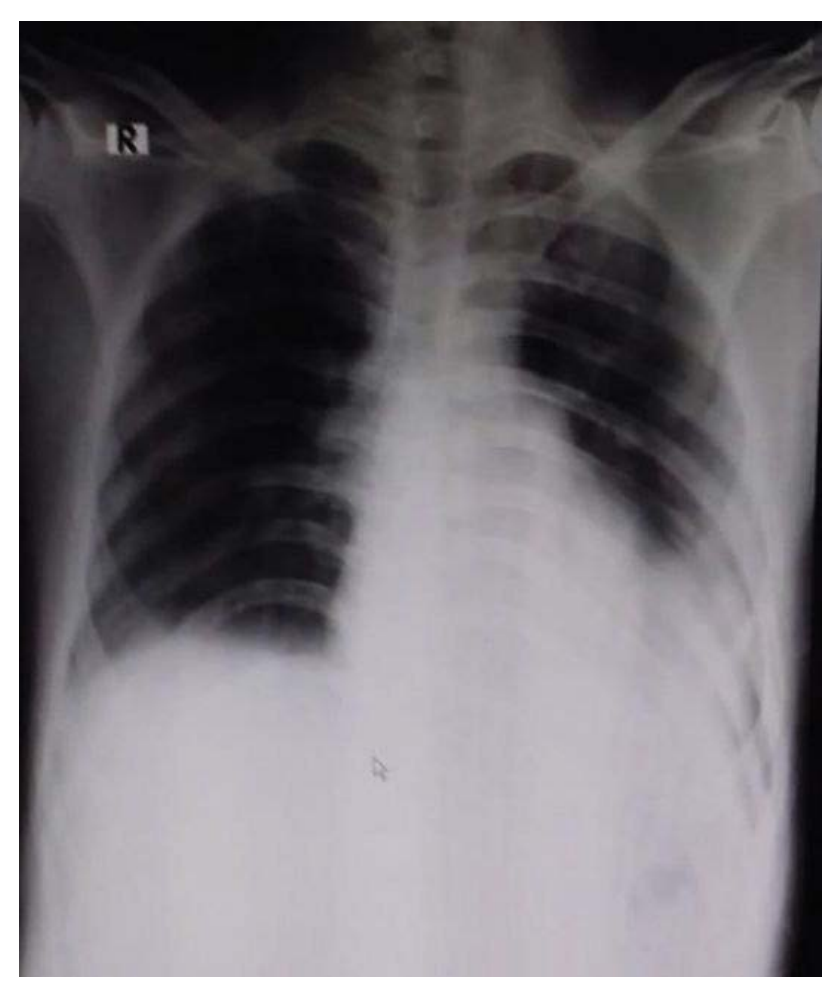

Figure 1: Chest X-ray Anteroposterior view showing bilateral peripheral and lower zone opacities more on left side.

ferritin $1000 \mathrm{ng} / \mathrm{mL}$ and D-dimer $1.26 \mathrm{mcg} / \mathrm{ml}$. His blood group was $O$ negative which was not available in the blood bank, thus he was transfused $O$ positive blood after obtaining consent from the patient. Tablet cefepime was added empirically. His blood cultures sent on day 1 did not showed any microbial growth. On day 6 of the hospital admission his oxygen requirement reduced to 2 $\mathrm{L} / \mathrm{min}$ but he became increasingly delirious and violent which was managed acutely with injection haloperidol and after psychiatry consultation he was started on tab quetiapine. Non-contrast CT brain done to rule out any intracranial bleed was reported as normal. On $8^{\text {th }}$ day of hospital admission his general condition improved and he was maintaining $\mathrm{SpO}_{2} 98 \%$ without oxygen. His inflammatory markers improved (CRP $28 \mathrm{mg} / \mathrm{L}$, IL-6 17 $\mathrm{pg} / \mathrm{ml})$. On $10^{\text {th }}$ day of hospitalization repeat nasopharyngeal swab for RT-PCR was sent, which came out to be negative and he was transferred to non-COVID facility in a stable condition.

\section{Discussion}

Aplastic anemia is a rare disease with incidence reported in United States 2.34 cases per million population per year. Better prognosis at 2 years is seen in young age and less severe disease [4]. The ongoing COVID-19 pandemic is caused by SARS-CoV-2 which is more contagious and more fatal as compared to influenza. Age $>70$ years, comorbidities like hypertension, diabetes mellitus, chronic pulmonary diseases and immunosuppression are described as a risk factor risk factors for severity in COVID-19 [5-7].

Aplastic anemia is associated with immunosup- pressed state either due tothe disease itself or due to the immunosuppressive medications given to treat these patients. A preliminary report by Filocamo, et al. showed that the patients of chronic rheumatologic disorders treated with Biologic Disease-Modifying Anti Rheumatic Drugs (b DMARD) developed fewer respiratory or other life threatening complications from COVID-19 as compared to general population [8]. Also in another systematic review the immunosuppressed children and adults were found to have better outcome in SARS-CoV-2 as compared to other comorbidities [9]. Barcellini, et al. in a case series reported not only the favorable outcome but also lower than expected incidence of COVID-19 pneumonia in autoimmune cytopenias [10]. The favorable prognosis in immunosuppressed patients might be attributed to the fact that it may limit the inflammatory reaction commonly associated with COVID-19. Keiffer, et al. reported a case in which they successfully used IL-6 receptor antibody, tocilizumab in a severe COVID-19 patient for the treatment of hyper-inflammatory response called cytokine storm [11]. Our patients have an uncomplicated course despite increased inflammatory markers at admission which gradually normalized in second week of illness. We just added dexamethasone $6 \mathrm{mg}$ once daily in addition to his regular cyclophosphamide therapy.

The flip side of this is that the immunosuppressed state in aplastic anemia leads to not only the increased risk of contracting highly contagious SARS-CoV-2 infection but also it increases the chances of developing the severe disease [6]. This highlights the importance of preventive measures like frequent hand washing, social distancing, avoiding crowded places and probably vaccination.

This case report sensitizes the physicians to the fact that the aplastic anemia patients if develops COVID-19 pneumonia can be successfully managed and usually undergo uncomplicated course probably because of the immunosuppressed state which prevents hyper-inflammatory response.

\section{References}

1. World Health Organization (2020) WHO Director-General's opening remarks at the media briefing on COVID-19 - 11 March 2020.

2. Ejaz H, Alsrhani A, Zafar A, Javed H, Junaid K, et al. (2020) COVID-19 and comorbidities: Deleterious impact on infected patients. J Infect Public Health 13: 1833-1839.

3. Akcabelen YM, Koca Yozgat A, Parlakay AN, Yarali N (2020) COVID-19 in a child with severe aplastic anemia. Pediatr Blood Cancer 67: e28443.

4. Montane E, Ibanez L, Vidal X, Ballarin E, Puig R, et al. (2008) Catalan group for study of agranulocytosis and aplastic anemia. Epidemiology of aplastic anemia: A prospective multicenter study. Haematologica 93: 518-523.

5. Feng Y, Ling Y, Bai T, Xie Y, Huang J, et al. (2020) COVID-19 with different severities: A multicenter study of clinical features. Am J Respir Crit Care Med 201: 1380-1388. 
6. Gao Y, Chen Y, Liu M, Shi S, Tiana J (2020) Impacts of immunosuppression and immunodeficiency on COVID-19: A systematic review and meta-analysis. J Infect 81: e93-e95.

7. Wu C, Chen X, Cai Y, Xia J, Zhou X, et al. (2020) Risk factors associated with acute respiratory distress syndrome and death in patients with coronavirus disease 2019 pneumonia in Wuhan, China. JAMA Intern Med 180: 934-943.

8. Filocamo G, Minoia F, Carbogno S, Costi S, Romano M, et al. (2020) Absence of severe complications from SARSCoV-2 infection in children with rheumatic diseases treated with biologic drugs. J Rheumatol.
9. Minotti C, Tirelli F, Barbieri E, Giaquinto C, Dona D (2020) How is immunosuppressive status affecting children and adults in SARS-CoV-2 infection? A systematic review. J Infect 81: e61-e66.

10. Barcellini W, Giannotta JA, Fattizzo B (2021) Are patients with autoimmune cytopenias at higher risk of covid-19 pneumonia? the experience of a reference center in northern italy and review of the literature. Front Immunol 11: 609198.

11. Keiffer G, French Z, Wilde L, Filicko-O'Hara J, Gergis U, et al. (2020) Case report: Tocilizumab for the treatment of SARS-CoV-2 infection in a patient with aplastic anemia. Front Oncol 10: 562625. 